\title{
Sexual activity by marital status and age: a comparative perspective
}

\author{
Philipp Ueffing*(i), Aisha N. Z. Dasgupta (D) and Vladimíra Kantorová(i) \\ Department of Economic and Social Affairs, United Nations Population Division, New York, USA \\ *Corresponding author. Email: ueffing@un.org
}

(Received 14 May 2019; revised 09 October 2019; accepted 10 October 2019; first published online 18 December 2019)

\begin{abstract}
This paper presents an analysis of trends in sexual activity by marital status and age, and their associations with contraceptive use. Understanding levels of, and trends in, sexual activity is important for assessing the needs for family planning services and for analysing commonly used family planning indicators. Data were taken from 220 Demographic and Health Surveys (DHSs) and 62 Multiple Indicator Cluster Surveys (MICSs) to provide insights into sexual activity by marital status and age in a total of 94 countries in different regions of the world. The results show the sensitivity of the indicator with respect to the definition of currently sexually active, based on the timing of last sexual intercourse (during the last 4 weeks, 3 months, or 1 year). Substantial diversity in sexual activity by marital status and age was demonstrated across countries. The proportion of married women reporting recent sexual activity (sexual intercourse during the last 4 weeks) ranged from $50 \%$ to $90 \%$. The proportion of unmarried women reporting recent sexual activity did not exceed $50 \%$ in any of the 94 countries with available data, but showed substantial regional differences: it appeared to be rare in Asia and extremely varied within Africa, Europe and Latin America and the Caribbean. Among married women, sexual activity did not vary much by age group, while for unmarried women, there was an inverted U-pattern by age, with the youngest age group (15-19 years old) having the lowest proportion sexually active. The proportion of women who reported currently using contraception and reported not being sexually active varied by the contraceptive method used and was overall much greater among unmarried women. The evidence presented in this paper can be used to improve family planning policies and programmes to serve the diverse needs, for example regarding method choice and service provision, of unmarried women.
\end{abstract}

Keywords: Sexual activity; Contraceptive use; Comparative perspective

\section{Introduction}

Understanding trends in sexual activity is important for the study of sexual health, populations at risk of pregnancy, HIV and other sexually transmitted infections, and to draw related policy implications. A large comparative study of sexual behaviour covering 59 countries showed substantial diversity in sexual behaviour by region and sex and examined interventions to improve sexual health (Wellings et al., 2006). A number of analyses using Demographic and Health Survey (DHS) data has looked at changes in sexual behaviours in the context of HIV (Cleland et al., 2004; Curtis \& Sutherland, 2004; Mishra et al., 2009; Wang et al., 2012), and have shown that part of the response to the HIV epidemic in sub-Saharan Africa has been to abstain or delay sexual debut among young unmarried women (Cleland \& Ali, 2006).

This study was motivated by the need to understand sexual activity as a component in the measurement of family planning indicators. Family planning indicators - such as current 
contraceptive use, unmet need and demand satisfied - have typically been reported for women who are married or in a union (from here on referred to as 'married women'). Women who are not married nor in a union (from here on referred to as 'unmarried women') have often been excluded from surveys or questions on reproductive behaviour and contraceptive use, or the results for unmarried women have not been published.

In an effort to provide comprehensive data for monitoring progress towards Sustainable Development Goal 3, Health Indicator 3.7.1., the proportion of women of reproductive age (15-49 years) who have their need for family planning satisfied with modern methods (United Nations, 2015, 2019), the United Nations Population Division has recently extended the data compilations of family planning indicators to all women of reproductive age, disaggregated by marital status and age (United Nations, 2017a).

The 'proximate determinants' framework for the analysis of fertility (Bongaarts, 1978) includes marital status, which serves as a proxy for sexual activity and exposure to pregnancy. However, since Bongaarts' initial work on the framework, the importance of sexual activity among unmarried women has been increasingly recognized and reported, and Bongaarts (2015) proposed the inclusion of sexual activity among unmarried women in the proximate determinants model. This called for a review of the validity of using marriage as a proxy for sexual activity.

Some researchers have suggested using sexual activity rather than marriage to indicate exposure to pregnancy and that differences across countries and over time in sexual activity should be included in the proximate determinants framework (Stover, 1998; Brown, 2000). In parts of sub-Saharan Africa, sexual inactivity played a role alongside traditional contraceptive methods in the onset of the fertility transition (Rossier \& Corker, 2017).

This paper examines the levels of, and trends in, sexual activity based on data from the DHS and Multiple Indicators Cluster Surveys (MICS) microdata for 94 countries. The analysis looked at four issues: the definition and measurement of recent sexual activity of women at reproductive ages; the levels of sexual activity by marital status and age; differences by geographic region and trends over time; and the association between reported sexual activity and reported current use of contraceptive methods. The Discussion section examines the implications for the interpretation of family planning indicators and for understanding of the needs for reproductive health services.

\section{Sexual activity and the measurement of family planning indicators}

Historically, the measurement of family planning indicators has been limited to the population of women who are married or in a union, as marital (or cohabiting union) status has been used as a proxy to identify sexually active women and, thus, the population at risk of pregnancy or potentially in need of family planning. In the past, the omission of women who were never married, widowed, divorced or separated was justified on the assumption that they had low levels of sexual activity and, therefore, were exposed to a low risk of pregnancy, or on the assumption that it would not be possible, or culturally acceptable, to ask unmarried women these types of questions. In fact, restricting family planning indicators to married women can exclude a considerable number of women who are at risk of becoming pregnant or have family planning needs. Unmarried women, especially those who are young, may have poorer access to reproductive health services than married women in their peak childbearing years.

The choice of the population of women for which family planning indicators are calculated has been widely discussed in the literature, starting with the analyses of contraceptive use indicators from the World Fertility Surveys (Sathar \& Chidambaram, 1984). Various definitions of population exposed to the risk of pregnancy could be considered, using as criteria being sexually active and excluding women who are infecund or pregnant. Fabic and Becker (2017) developed an Alternative Contraceptive Prevalence Rate that measures contraceptive use among women who are sexually active, fecund and not pregnant, irrespective of marital status, using DHS data. They showed the crucial effect of the definition of current sexual activity on their measurement of 
contraceptive prevalence. In the case of unmet need for family planning, Bradley and Casterline (2014) tested the impacts that different assumptions of sexual activity have on the indicator of unmet need among married and unmarried women. On average, the estimated proportion of married women having unmet need dropped by 3.4 percentage points when women having no/infrequent sex were treated as having no unmet need. Bell and Bishai (2017) found significant differences in sexual activity between women with unmet need for family planning and women using contraceptives for spacing or limiting, and they suggested that despite being categorized as having an unmet need, many women may nevertheless be taking measures to control their fertility through regulating the frequency of marital coitus, thus reducing their risk of unintended pregnancy.

Although it is generally assumed that all married women are sexually active, in some countries in Africa postpartum abstinence is common, lasting up to 1-2 years (Caldwell \& Caldwell, 1990; Bledsoe, 2002), which has an impact on fertility, as compared with shorter periods of postpartum abstinence in other parts of the world, such as 'doing the month' in China or cuarentena in some countries of Latin America and the Caribbean (Kim-Godwin, 2003; Selin \& Stone, 2009). Terminal abstinence - the Grandmother Rule - is practised in some parts of Western Africa at the time of becoming a grandmother (Bledsoe, 2002). In other contexts, temporary spousal separation occurs due to seasonal or longer-term migration (Agadjanian et al., 2011; Sevoyan \& Agadjanian, 2013).

Sexual activity among unmarried women can be even more dependent on cultural context. First, acceptability of sex among unmarried women varies from countries where it is widely accepted (e.g. countries in Europe, Northern America and some parts of Latin America and the Caribbean), to others where sex among unmarried people is predominantly considered unacceptable (e.g. in Western Asia, Northern Africa) (Pew Research Centre, 2014). Cultural acceptability of sex among unmarried women is likely to influence their sexual activity and contraceptive choices, which has implications for family planning programmes.

In cases where family planning indicators are reported for unmarried women, they have usually been reported for a subset of unmarried women - those who are sexually active, defined as those who indicate having had intercourse over a retrospective time frame, typically 4 weeks or 3 months (MacQuarrie, 2014; DHS StatCompiler, 2017). While there has been interest in studying sexual activity of young unmarried women as they are a group marginalized from family planning services in some parts of the world (Gage-Brandon \& Meekers, 1993; Gage \& Meekers, 1994; Meekers, 1994; Blanc \& Way, 1998; Zaba et al., 2004), research on sexual activity among unmarried women in older ages (including women who are divorced, widowed or never married) is lacking.

As the need to assess contraceptive prevalence expands to unmarried women, it is important to understand the levels and trends of sexual activity among them and the different levels and age patterns of sexual activity across countries and world regions. Analysing sexual activity by marital status and age draws attention to some of the current challenges in the measurement and interpretation of family planning indicators.

\section{Methods}

This analysis used data for women of reproductive age (15-49 years old) from individual-level (micro) datasets of two international household survey programmes: the Demographic and Health Survey (DHS) and Multiple Indicator Cluster Survey (MICS). The DHS is a programme with support from United States Agency for International Development to collect, analyse and disseminate data on population, health, HIV and nutrition through more than 300 surveys in over 90 countries. The MICS programme is run by the United Nations Children Fund to generate data on the well-being of children and women in more than 300 surveys in over 100 countries. Only nationally representative surveys are included. The question used to ascertain recent sexual 
activity was available in 220 DHS surveys across 74 countries and in 62 MICS surveys across 45 countries, which have resulted in a total of 282 surveys for 94 low- or middle-income countries, which were included in this analysis.

Previous studies have concluded that reporting of sexual behaviour appears to be highly sensitive to survey design and that the trends cannot be tracked using estimates from different survey designs (Cleland et al., 2004). Despite some differences between MICS and DHS programmes, the wording of the questions regarding recent sexual activity and the overall structure of the sections of the questionnaires regarding demographic and reproductive health variables are comparable. The inclusion of MICSs has the advantage of an expanded coverage of countries and time trends. Nevertheless, when comparing data from different surveys over time within a country, it is important to keep in mind possible inconsistencies between MICS and DHS surveys that could influence the observations.

Cultural acceptability of sex among unmarried women may influence data collection and, consequently, the availability and quality of data to research unmarried women across countries. Many surveys are limited by asking questions about reproduction and sexuality to ever-married or currently married women only. The DHS and MICS surveys provide information on marital status and age, but not all surveys pose the question on sexual activity to unmarried women. For the analysis of sexual activity among unmarried women, data are available for 259 surveys across 83 countries. The increased data availability on sexual activity of unmarried women over time signals greater recognition that sexual activity is becoming more common among unmarried women, at least in some parts of the world. For example, in Asia, the recent DHS or MICS surveys of India, Nepal and Thailand now include unmarried women in the sexual activity questions, whereas previously they had been excluded. To advance research in this area, it is crucial to identify where the data availability for unmarried women is deficient. For instance, a large number of countries in Northern Africa, Southern Asia, South-eastern Asia and Western Asia do not collect data for never-married women in DHS and MICS surveys.

For those surveys that do ask unmarried women about their sexual activity, it is likely that sexual activity is under-reported. Young unmarried women, as well as formerly married women, may feel uncomfortable answering questions regarding their sexual behaviour, which in some settings is stigmatized. Studies from Africa on use of different survey methods to obtain information on sexual behaviour have indicated that in face-to-face interviewing, young unmarried women tend to under-report their sexual activity. The most striking evidence came from a study in Kenya that collected both survey data and blood and urine samples. This study found that among women aged 15-24 years, who claimed never to have had sex, STI/HIV rates ranged from 6 to 18\% (Buve et al., 2001). These so-called 'virgin infections' are one example of evidence of young women under-reporting sexual activity.

The largest number of countries for which DHS or MICS data are available are in Africa (40 countries): four in Southern Africa, thirteen in Eastern Africa, eight in Middle Africa and fifteen in Western Africa. Morocco is the only country in Northern Africa for which data were available and it was grouped for analytical purposes together with the three Western Asian countries. Mongolia was the only country in Eastern Asia included in the analysis and was grouped together with eleven South-Central Asian countries. For South-Eastern Asia, data were available for eight countries, bringing the total for Asia to 24 countries. Data were not available for China, the most populous country in Asia. The analysis included eight countries in Europe, a select group through the MICS programme: three in Eastern Europe and five in Southern Europe. These countries are among the poorer in the region. Data were available for 22 countries in Latin America and the Caribbean. Populous countries such as Argentina and Chile were missing from the data compilation, and Brazil was only represented by a DHS from 1996. Therefore, the countries for which data were available were not necessarily representative of their regions; this was particularly the case for Europe. Table 1 lists all the countries included in the analysis by region and sub-region. 
Table 1. Percentage of women aged 15-49 who were sexually active in the last 4 weeks before the survey using most recent datasets, 1987-2016

\begin{tabular}{|c|c|c|c|c|c|c|c|}
\hline \multirow[b]{2}{*}{ Country } & \multirow[b]{2}{*}{ ISO-Code } & \multirow[b]{2}{*}{ Major area } & \multirow[b]{2}{*}{ Region } & \multirow[b]{2}{*}{ Most recent year } & \multirow[b]{2}{*}{ Survey } & \multicolumn{2}{|c|}{ Percentage of women sexually active } \\
\hline & & & & & & Married/In union & $\begin{array}{l}\text { Unmarried/Not } \\
\text { in union }\end{array}$ \\
\hline Afghanistan & AFG & Asia & South-Central Asia & 2015 & DHS & 88.9 & \\
\hline Albania & ALB & Europe & Southern Europe & 2008 & DHS & 85.6 & 5.9 \\
\hline Angola & AGO & Africa & Middle Africa & 2015 & DHS & 72.7 & 24.2 \\
\hline Armenia & ARM & Asia & Western Asia & 2010 & DHS & 83.8 & 0.8 \\
\hline Azerbaijan & AZE & Asia & Western Asia & 2006 & DHS & 85.8 & \\
\hline Bangladesh & BGD & Asia & South-Central Asia & 2014 & DHS & 82.7 & \\
\hline Barbados & BRB & LAC & Caribbean & 2012 & MICS & 79.1 & 14.7 \\
\hline Belarus & BLR & Europe & Eastern Europe & 2012 & MICS & 89.3 & 29.7 \\
\hline Belize & BLZ & LAC & Central America & 2011 & MICS & 87.3 & 19.6 \\
\hline Benin & BEN & Africa & Western Africa & 2014 & MICS & 64.1 & 21.9 \\
\hline Bhutan & BTN & Asia & South-Central Asia & 2010 & MICS & 80 & 1.2 \\
\hline Bolivia (Plurinational State of) & BOL & LAC & South America & 2008 & DHS & 74.3 & 9 \\
\hline Bosnia and Herzegovina & $\mathrm{BIH}$ & Europe & Southern Europe & 2011 & MICS & 88.6 & 18 \\
\hline Brazil & BRA & LAC & South America & 1996 & DHS & 91.8 & 18 \\
\hline Burkina Faso & BFA & Africa & Western Africa & 2010 & DHS & 58.8 & 9.5 \\
\hline Burundi & BDI & Africa & Eastern Africa & 2010 & DHS & 88.1 & 2.2 \\
\hline Cambodia & KHM & Asia & South-Eastern Asia & 2014 & DHS & 83.1 & 0.7 \\
\hline Cameroon & CMR & Africa & Middle Africa & 2014 & MICS & 74.9 & 27.2 \\
\hline Central African Republic & CAF & Africa & Middle Africa & 2010 & MICS & 61 & 17.5 \\
\hline Chad & TCD & Africa & Middle Africa & 2014 & DHS & 75.6 & 8.1 \\
\hline Colombia & $\mathrm{COL}$ & LAC & South America & 2015 & DHS & 87.3 & 25.8 \\
\hline
\end{tabular}


Table 1. (Continued)

\begin{tabular}{|c|c|c|c|c|c|c|c|}
\hline \multirow[b]{2}{*}{ Country } & \multirow[b]{2}{*}{ ISO-Code } & \multirow[b]{2}{*}{ Major area } & \multirow[b]{2}{*}{ Region } & \multirow[b]{2}{*}{ Most recent year } & \multirow[b]{2}{*}{ Survey } & \multicolumn{2}{|c|}{ Percentage of women sexually active } \\
\hline & & & & & & Married/In union & $\begin{array}{l}\text { Unmarried/Not } \\
\text { in union }\end{array}$ \\
\hline Comoros & $\mathrm{COM}$ & Africa & Eastern Africa & 2012 & DHS & 76 & 4.2 \\
\hline Congo & COG & Africa & Middle Africa & 2011 & DHS & 77 & 33 \\
\hline Costa Rica & CRI & LAC & Central America & 2011 & MICS & 87.3 & 24.1 \\
\hline Côte d'Ivoire & $\mathrm{CIV}$ & Africa & Western Africa & 2011 & DHS & 67.5 & 31.5 \\
\hline Cuba & CUB & LAC & Caribbean & 2014 & MICS & 93.5 & 47.4 \\
\hline Democratic Republic of the Congo & COD & Africa & Middle Africa & 2013 & DHS & 73.2 & 19.5 \\
\hline Dominican Republic & DOM & LAC & Caribbean & 2014 & MICS & 87.4 & 22.3 \\
\hline El Salvador & SLV & LAC & Central America & 2014 & MICS & 81.7 & 11.3 \\
\hline Ethiopia & ETH & Africa & Eastern Africa & 2016 & DHS & 80.5 & 3 \\
\hline Gabon & GAB & Africa & Middle Africa & 2012 & DHS & 72.1 & 37.2 \\
\hline Gambia & GMB & Africa & Western Africa & 2013 & DHS & 60.4 & 2.1 \\
\hline Ghana & GHA & Africa & Western Africa & 2014 & DHS & 62.5 & 17.4 \\
\hline Guatemala & GTM & LAC & Central America & 2014 & DHS & 80.7 & 6.6 \\
\hline Guinea & GIN & Africa & Western Africa & 2012 & DHS & 50.3 & 16 \\
\hline Guinea-Bissau & GNB & Africa & Western Africa & 2014 & MICS & 55.6 & 38.3 \\
\hline Guyana & GUY & LAC & South America & 2014 & MICS & 75.4 & 6.1 \\
\hline Haiti & HTI & LAC & Caribbean & 2012 & DHS & 72.7 & 14.8 \\
\hline Honduras & HND & LAC & Central America & 2011 & DHS & 83.9 & 10.1 \\
\hline India & IND & Asia & South-Central Asia & 2005 & DHS & 73.2 & 0.3 \\
\hline Indonesia & IDN & Asia & South-Eastern Asia & 2012 & DHS & 80.6 & 0.3 \\
\hline Jordan & JOR & Asia & Western Asia & 2007 & DHS & 90.9 & \\
\hline Kazakhstan & KAZ & Asia & South-Central Asia & 2015 & MICS & 91.3 & 15.8 \\
\hline
\end{tabular}


Table 1. (Continued)

\begin{tabular}{|c|c|c|c|c|c|c|c|}
\hline \multirow[b]{2}{*}{ Country } & \multirow[b]{2}{*}{ ISO-Code } & \multirow[b]{2}{*}{ Major area } & \multirow[b]{2}{*}{ Region } & \multirow[b]{2}{*}{ Most recent year } & \multirow[b]{2}{*}{ Survey } & \multicolumn{2}{|c|}{ Percentage of women sexually active } \\
\hline & & & & & & Married/In union & $\begin{array}{l}\text { Unmarried/Not } \\
\text { in union }\end{array}$ \\
\hline Kenya & KEN & Africa & Eastern Africa & 2014 & DHS & 79.4 & 7 \\
\hline Kyrgyzstan & KGZ & Asia & South-Central Asia & 2012 & DHS & 87.4 & 3.4 \\
\hline Lao People's Democratic Republic & LAO & Asia & South-Eastern Asia & 2011 & MICS & 86.6 & 1.6 \\
\hline Lesotho & LSO & Africa & Southern Africa & 2014 & DHS & 62.2 & 14.3 \\
\hline Liberia & LBR & Africa & Western Africa & 2013 & DHS & 68.4 & 39.9 \\
\hline Madagascar & MDG & Africa & Eastern Africa & 2008 & DHS & 85.5 & 14.6 \\
\hline Malawi & MWI & Africa & Eastern Africa & 2015 & DHS & 77.9 & 9.5 \\
\hline Mali & MLI & Africa & Western Africa & 2015 & MICS & 81.4 & 13.4 \\
\hline Mauritania & MRT & Africa & Western Africa & 2000 & DHS & 68.1 & \\
\hline Mexico & MEX & LAC & Central America & 2015 & MICS & 80.4 & 18.6 \\
\hline Mongolia & MNG & Asia & Eastern Asia & 2013 & MICS & 84.4 & 14.8 \\
\hline Montenegro & MNE & Europe & Southern Europe & 2013 & MICS & 88.3 & 26 \\
\hline Morocco & MAR & Asia & Northern Africa & 1992 & DHS & 87.7 & \\
\hline Mozambique & MOZ & Africa & Eastern Africa & 2011 & DHS & 69.4 & 27 \\
\hline Myanmar & MMR & Asia & South-Eastern Asia & 2015 & DHS & 77.7 & 0.3 \\
\hline Namibia & NAM & Africa & Southern Africa & 2013 & DHS & 73.8 & 22.4 \\
\hline Nepal & NPL & Asia & South-Central Asia & 2016 & DHS & 62.3 & 0.1 \\
\hline Nicaragua & NIC & LAC & Central America & 2001 & DHS & 82.6 & 7 \\
\hline Niger & NER & Africa & Western Africa & 2012 & DHS & 69.8 & 1.4 \\
\hline Nigeria & NGA & Africa & Western Africa & 2013 & DHS & 78.5 & 13.8 \\
\hline Pakistan & PAK & Asia & South-Central Asia & 2012 & DHS & 70.5 & \\
\hline
\end{tabular}


Table 1. (Continued)

\begin{tabular}{|c|c|c|c|c|c|c|c|}
\hline \multirow[b]{2}{*}{ Country } & \multirow[b]{2}{*}{ ISO-Code } & \multirow[b]{2}{*}{ Major area } & \multirow[b]{2}{*}{ Region } & \multirow[b]{2}{*}{ Most recent year } & \multirow[b]{2}{*}{ Survey } & \multicolumn{2}{|c|}{ Percentage of women sexually active } \\
\hline & & & & & & Married/In union & $\begin{array}{c}\text { Unmarried/Not } \\
\text { in union }\end{array}$ \\
\hline Panama & PAN & LAC & Central America & 2013 & MICS & 86.1 & 21.5 \\
\hline Paraguay & PRY & LAC & South America & 2016 & MICS & 89.1 & 25 \\
\hline Peru & PER & LAC & South America & 2012 & DHS & 83.7 & 16.8 \\
\hline Philippines & $\mathrm{PHL}$ & Asia & South-Eastern Asia & 2013 & DHS & 73.6 & 2.9 \\
\hline Republic of Moldova & MDA & Europe & Eastern Europe & 2012 & MICS & 79.9 & 17.8 \\
\hline Rwanda & RWA & Africa & Eastern Africa & 2014 & DHS & 91.5 & 4.7 \\
\hline Saint Lucia & LCA & LAC & Caribbean & 2012 & MICS & 86 & 21 \\
\hline Sao Tome and Principe & STP & Africa & Middle Africa & 2014 & MICS & 86.2 & 23.2 \\
\hline Senegal & SEN & Africa & Western Africa & 2016 & DHS & 66.6 & 1.4 \\
\hline Serbia & SRB & Europe & Southern Europe & 2010 & MICS & 87.2 & 40.8 \\
\hline Sierra Leone & SLE & Africa & Western Africa & 2013 & DHS & 59.9 & 35.1 \\
\hline South Africa & ZAF & Africa & Southern Africa & 1998 & DHS & 78.1 & 30.4 \\
\hline Sri Lanka & LKA & Asia & South-Central Asia & 1987 & DHS & 76.9 & \\
\hline Sudan & SDN & Africa & Eastern Africa & 1989 & DHS & 65.9 & \\
\hline Suriname & SUR & LAC & South America & 2010 & MICS & 86.7 & 31.6 \\
\hline Swaziland & SWZ & Africa & Southern Africa & 2014 & MICS & 73.5 & 19.5 \\
\hline Tajikistan & TJK & Asia & South-Central Asia & 2012 & DHS & 66.3 & \\
\hline Thailand & THA & Asia & South-Eastern Asia & 1987 & DHS & 77.9 & \\
\hline TFYR Macedonia & MKD & Europe & Southern Europe & 2005 & MICS & 80.4 & 10.5 \\
\hline
\end{tabular}




\begin{tabular}{|c|c|c|c|c|c|c|c|}
\hline \multirow[b]{2}{*}{ Country } & \multirow[b]{2}{*}{ ISO-Code } & \multirow[b]{2}{*}{ Major area } & \multirow[b]{2}{*}{ Region } & \multirow[b]{2}{*}{ Most recent year } & \multirow[b]{2}{*}{ Survey } & \multicolumn{2}{|c|}{ Percentage of women sexually active } \\
\hline & & & & & & Married/In union & $\begin{array}{l}\text { Unmarried/Not } \\
\text { in union }\end{array}$ \\
\hline Timor-Leste & TLS & Asia & South-Eastern Asia & 2009 & DHS & 75.5 & 0.5 \\
\hline Togo & TGO & Africa & Western Africa & 2013 & DHS & 61.9 & 18.8 \\
\hline Trinidad and Tobago & TTO & LAC & Caribbean & 1987 & DHS & 85.8 & 1.6 \\
\hline Uganda & UGA & Africa & Eastern Africa & 2011 & DHS & 75.4 & 9.8 \\
\hline Ukraine & UKR & Europe & Eastern Europe & 2012 & MICS & 88.3 & 20.3 \\
\hline United Republic of Tanzania & TZA & Africa & Eastern Africa & 2015 & DHS & 79.6 & 17.6 \\
\hline Uruguay & URY & LAC & South America & 2012 & MICS & 89.8 & 42 \\
\hline Uzbekistan & UZB & Asia & South-Central Asia & 2006 & MICS & 88.9 & 0.3 \\
\hline Viet Nam & VNM & Asia & South-Eastern Asia & 2010 & MICS & 82.9 & 0.9 \\
\hline Zambia & ZMB & Africa & Eastern Africa & 2013 & DHS & 84.6 & 12.6 \\
\hline Zimbabwe & ZWE & Africa & Eastern Africa & 2015 & DHS & 82.4 & 8.6 \\
\hline
\end{tabular}


For both DHS and MICS, the data compilation used standardized variable names and codes on sexual activity, marital status, current use of contraceptive methods and appropriate survey weights to facilitate analysis across surveys. A measure of sexual activity was obtained from the question on the timing of last intercourse (typically worded in DHS and MICS as: When was the last time you had sexual intercourse?) and from information on whether a woman has ever had intercourse from the question on the age at first intercourse (typically worded in DHS and MICS: How old were you when you had sexual intercourse for the very first time?). Information from these two questions was combined because the question on age at first intercourse commonly precedes the question on timing of last intercourse and filters out respondents who have never had intercourse. Incomplete or inconsistent responses were excluded except for one case. In DHS data, responses of timing since last intercourse that were inconsistent with the timing of last birth were recoded to 'before last birth' and treated as cases where the timing of last sexual intercourse exceeded one year.

The first section of the results presents a sensitivity analysis to test the impact of different definitions of current sexual activity, according to the time of last sexual intercourse ('last sex', henceforth). Thereafter, unless specifically stated otherwise, women were considered to be sexually active if they reported having had sex within the last 4 weeks. This time frame to determine current sexual activity was applied in DHS and MICS for the measurement of unmet need for family planning among unmarried women (Bradley et al., 2012).

\section{Results}

\section{Sexual activity of women of reproductive age}

The number of women of reproductive age (15-49 years old) who are classified as currently sexually active depends strongly on the time frame of 'last sex' used to define being currently sexually active. Substantially more women appear to be sexually active when a longer time frame is applied. Figures 1 and 2 shows the steep gradient of the cumulative percentage of married and unmarried women, respectively, who were sexually active in the last 4 weeks, 3 months and 1 year, and more than 1 year ago (also referred to as 'ever had sex').

Among married women (Fig. 1), the proportion of women who had sex in the last 4 weeks is around 50\% in Guinea and Guinea-Bissau and above $90 \%$ for nine countries in the sample (Bosnia and Herzegovina, Brazil, Cuba, Jordan, Kazakhstan, Paraguay, Rwanda, Trinidad and Tobago and Uzbekistan). When applying a time frame of sexual intercourse within the last 3 months, current sexual activity in almost half of the countries remains below $90 \%$. Even when the definition is extended to 1 year, a considerable proportion of married women have not been currently sexually active, especially in countries in Western Africa. Only when the definition is expanded to 'ever had sex', are nearly all married women reported to be sexually active. The steepest increase in the proportion of women who are sexually active when the time frame is expanded to 3 months or 1 year could be observed in most countries in Western Africa (e.g. Burkina Faso, Guinea, Guinea-Bissau and Senegal) and in some countries in Middle Africa (Central African Republic and Democratic Republic of the Congo) and Asia (Nepal and Tajikistan). Within Latin America and the Caribbean, Bolivia, Guyana and Haiti stand out at the lower end of married women being sexually active within the last 4 weeks.

For unmarried women (Fig. 2), the increase in the proportion of women who are classified as sexually active increases steeply when extending the definition of sexual activity beyond the last 4 weeks. The proportion of women who are sexually active at each of the four periods varies greatly within regions, but generally, increases with similar increments over the four intervals. In Cuba, for instance, where sexual activity is the highest for unmarried women among all observed countries, sexual activity rises from the high starting value of $47 \%$ of women sexually active within the last 4 weeks, to $59 \%$ active within the last 3 months, to $73 \%$ within the 

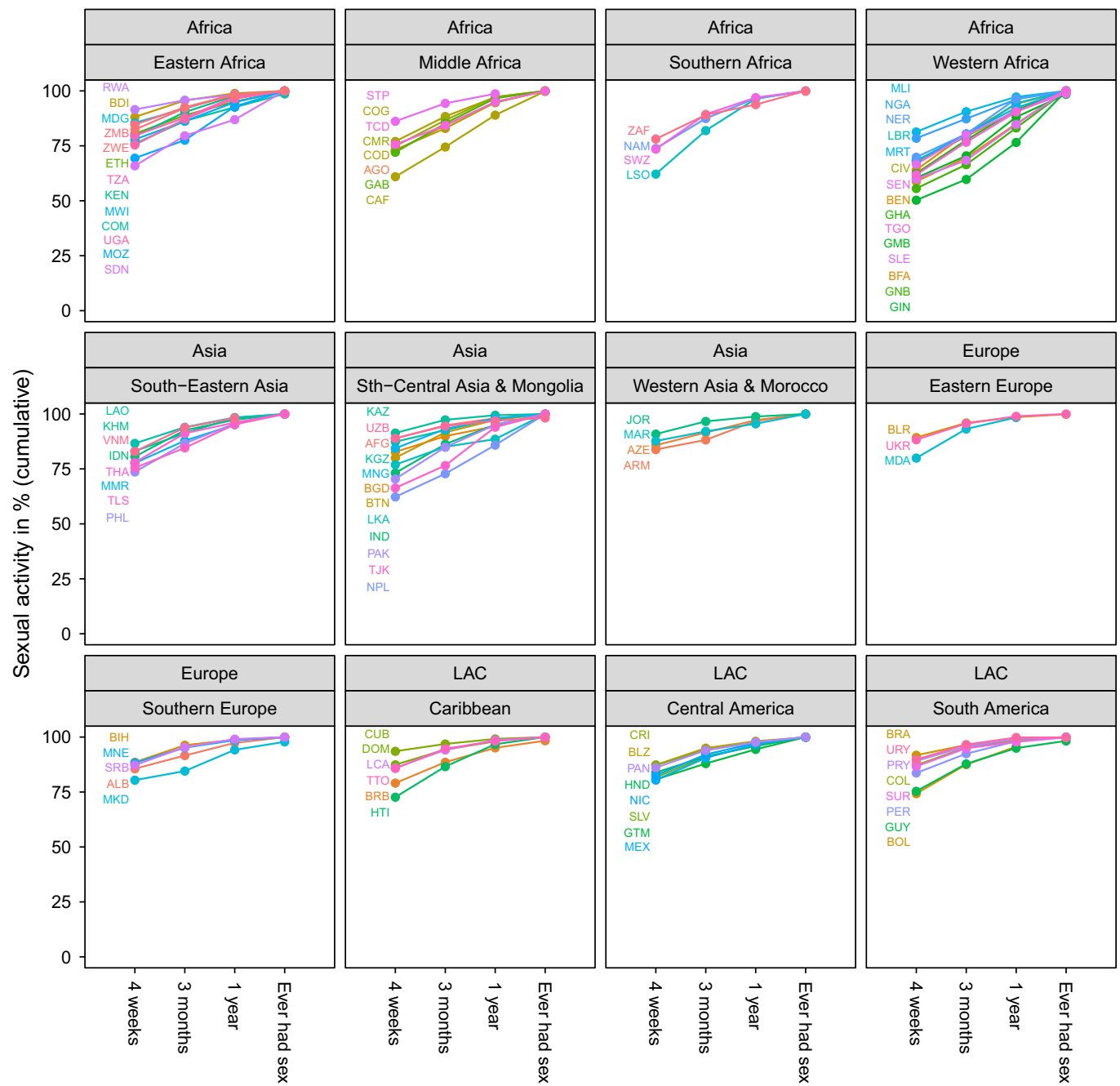

Figure 1. Timing of last sexual intercourse among married women by country based on DHS and MICS micro datasets; most recent estimates for each country (between 1987 and 2016). Results shown by United Nations regions and sub-regions, except Mongolia, which is presented with South-Central Asia, and Morocco, which is presented with Western Asia. Country names represented by three-letter ISO codes (see Table 1). LAC: Latin America and the Caribbean.

last year, to $87 \%$ who ever had sex. At the same time, Burkina Faso, where sexual activity within the last 4 weeks is relatively low at $10 \%$, also experiences a considerable incremental increase to around $25 \%$ sexually active within the last year. Exceptions are countries where sexual activity within the last 4 weeks among unmarried women is very low at less than 5\% (Armenia, India, Nepal and Timor-Leste). Here the proportion of unmarried women who are sexually active remains low despite extending the time frame and an increase only occurs when the interval of greater than 1 year is applied, which could be explained by formerly married women who have not been sexually active since becoming widowed or divorced. In South-Central Asia, Kazakhstan stands out at the upper end for this sub-region, together with Mongolia, which is part of Eastern Asia.

These results demonstrate the sensitivity of the definition of being currently sexually active according to timing of last sex. Further analysis applied the 4-week definition of sexual activity 

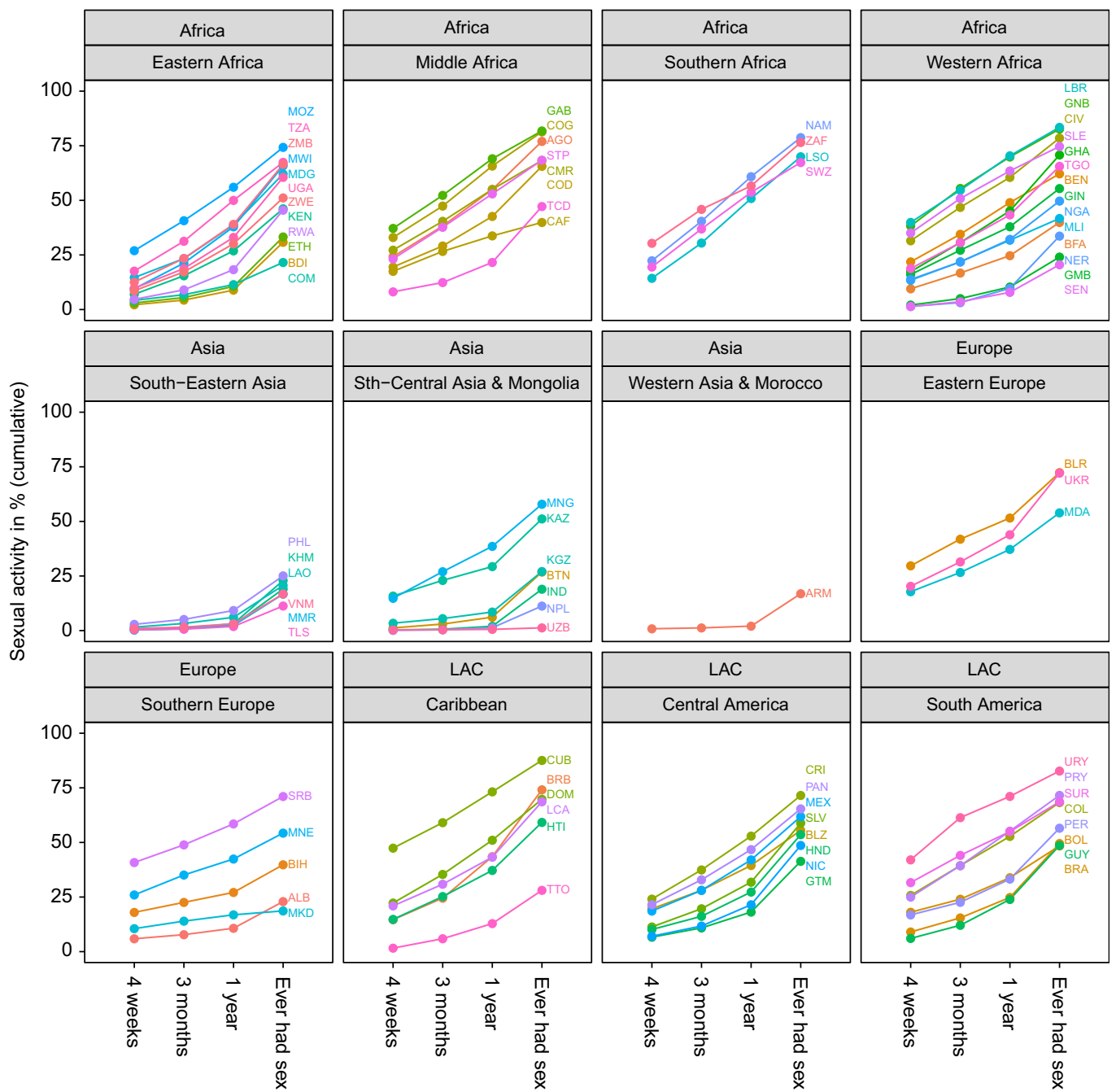

Figure 2. Timing of last sexual intercourse among unmarried women by country based on DHS and MICS micro datasets; most recent estimates for each country (between 1987 and 2016). Results shown by United Nations regions and sub-regions, except Mongolia, which is presented with South-Central Asia, and Morocco, which is presented with Western Asia. Country names represented by three-letter ISO codes (see Table 1). LAC: Latin America and the Caribbean.

as it is most commonly used in calculating family planning among unmarried sexually active (MacQuarrie, 2014; DHS Statcompiler, 2017) and has been argued elsewhere to best reflect current behaviour (Fabic \& Becker, 2017).

\section{Women's sexual activity by marital status}

The percentage of women who are sexually active (defined as having sex within the last 4 weeks) by four categories of marital status is presented in Figure 3, by major area (most recent estimate for each country, see also Table 1). Boxplots are used to depict the distribution of country estimates by sub-region. Among married women, the proportion of women who are sexually active ranges from $50 \%$ (e.g. in Guinea) to over $90 \%$ (e.g. in Rwanda), confirming earlier findings of considerable differences in coital frequency for a smaller sample of sub-Saharan African 

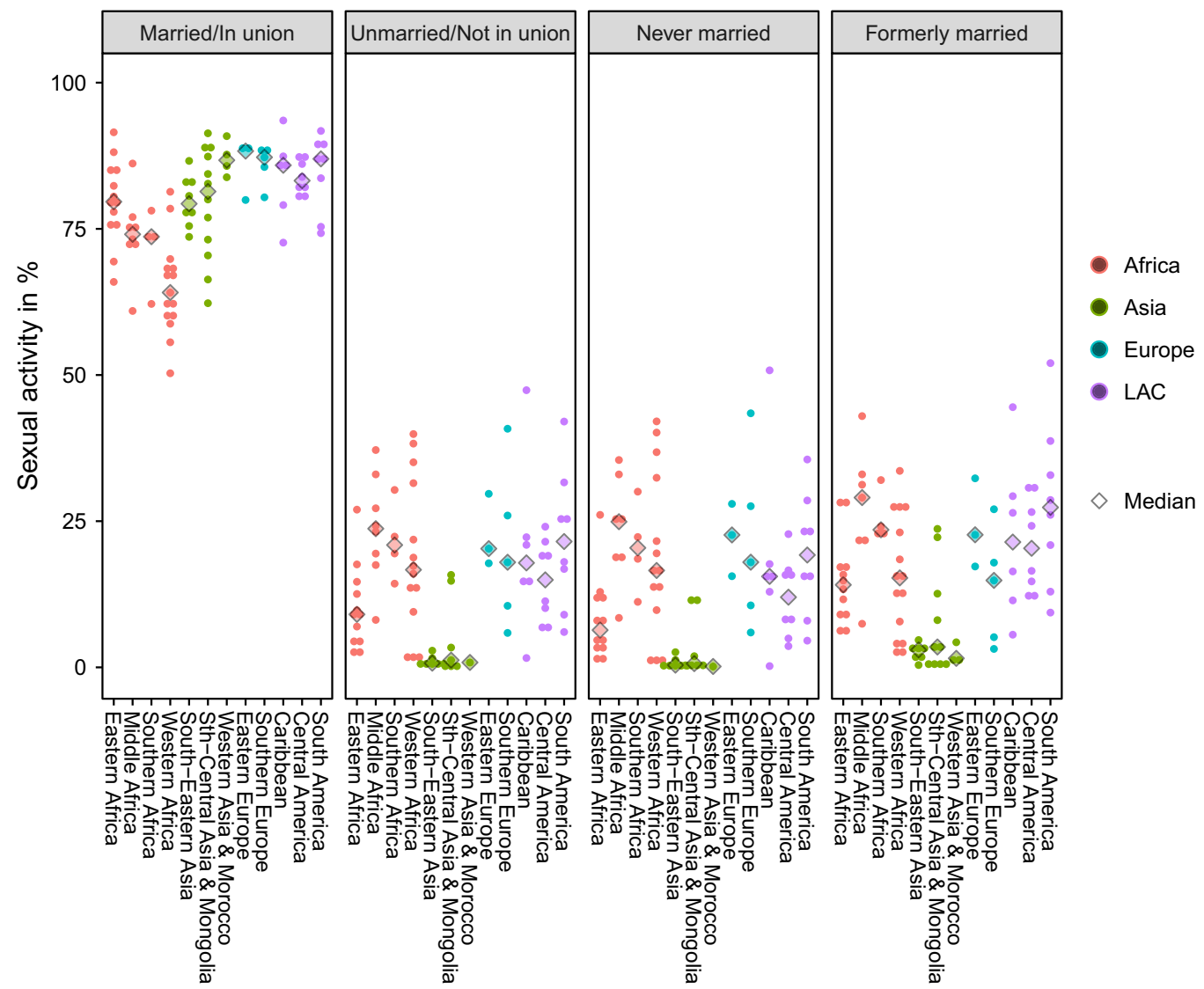

Figure 3. Proportion of women sexually active in last 4 weeks in each sub-region (married, unmarried, never married and formerly married) based on DHS and MICS micro datasets; most recent estimates for each country (between 1987 and 2016). Results shown by United Nations regions and sub-regions, except Mongolia, which is presented with South-Central Asia, and Morocco, which is presented with Western Asia. LAC: Latin America and the Caribbean.

countries (Brown, 2000) and challenging the assumption that all married women are sexually active. Countries with lower levels of marital sexual activity are located in Middle Africa, Southern Africa and Western Africa. For the countries in Eastern Europe, Southern Europe, Western Asia and Latin America and the Caribbean, the proportion of married women who had sexual intercourse within the last 4 weeks is consistently at higher levels, generally above $75 \%$, though with significant diversity within the Caribbean.

Sexual activity among unmarried women in the Asian countries included in the analysis is rare (the exceptions are Kazakhstan at $16 \%$ and Mongolia at 20\%). For Africa, Europe and Latin America and Caribbean, there is great diversity among the countries, but the proportion of unmarried women who are sexually active does not exceed $47 \%$. Sexual activity among unmarried women ranges from less than 7\% in Guatemala and Senegal to around $40 \%$ in other countries across these regions (Cuba, Liberia, Serbia and Uruguay). In four countries in Southern Europe included in this analysis, the proportion of unmarried women who are sexually active ranges from around 6\% in Albania to around 40\% in Serbia.

The group of unmarried women refers to those who have never been married and those who were formerly married. Formerly married women - consisting of women who are separated, divorced or widowed - are preponderantly older than never-married women and of reproductive age (15-49 years); the majority of unmarried women in all countries have never been married 


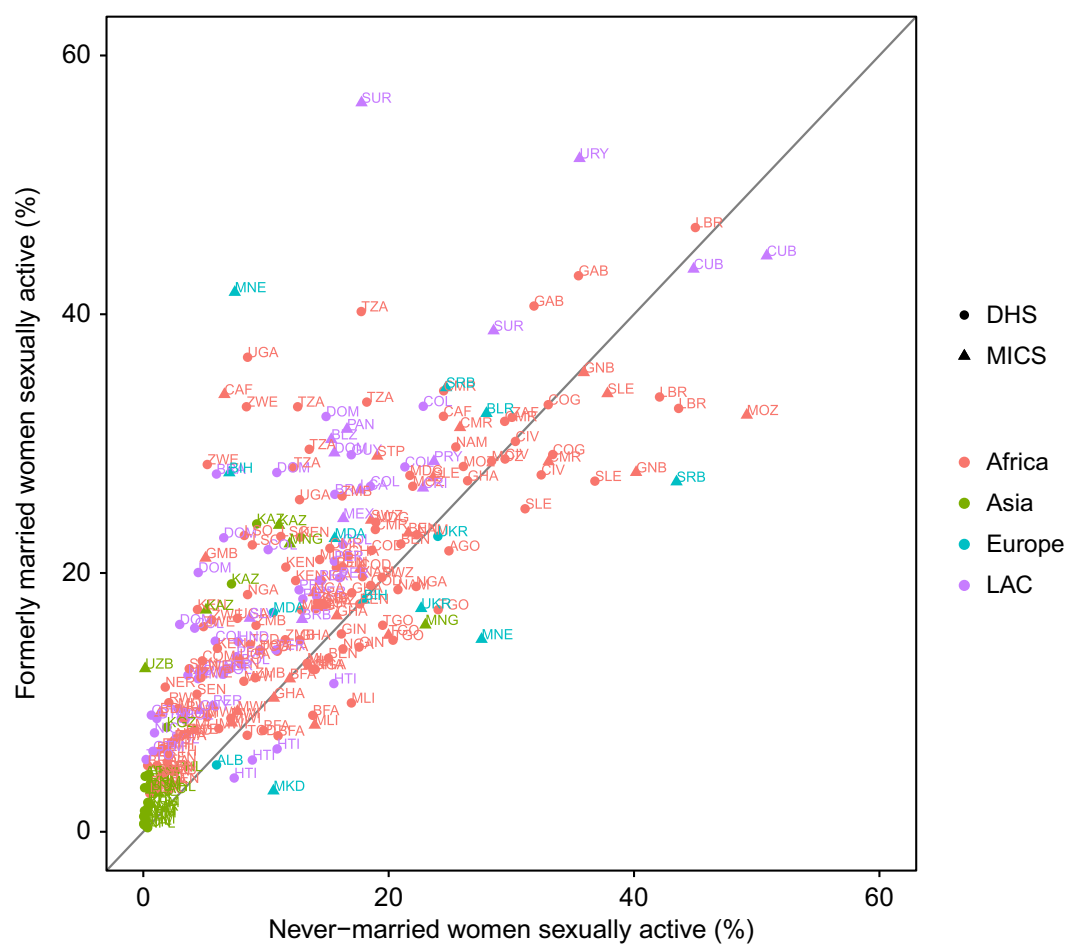

Figure 4. Comparison of sexual activity (in last 4 weeks) among formerly and never-married women based on DHS and MICS micro datasets; most recent estimates for each country (between 1987 and 2016). Results shown by United Nations regions. Country names represented by three-letter ISO codes (see Table 1). LAC: Latin America and the Caribbean.

(United Nations, 2017b). Despite the differences in age and family situation, the level of sexual activity is roughly similar for never- and formerly married women (Fig. 3).

In order to identify countries for which the level of sexual activity is different for never- and formerly married women, the proportion of never-married women who are sexually active has been plotted against the proportion of formerly married women who are sexually active (Fig. 4). The identity line indicates the same proportion of sexual activity among never-married and formerly married women. The data show a somewhat greater number of countries above the identity line than below it, suggesting that formerly married women are slightly more sexually active than never-married women. In countries where the reported sexual activity among unmarried women is very low (mainly in South-Central Asia, South-Eastern Asia and Western Asia), the proportion of formerly married women reporting recent sexual activity is consistently higher than among never-married women. In Latin America and the Caribbean, sexual activity is on average slightly higher among formerly married women (for example, in Brazil and the Dominican Republic) than for never-married women. There are some examples in Western Africa where sexual activity is higher among never-married women compared with formerly married women (Benin, Liberia and Togo). Since the levels of sexual activity are broadly similar for never-married and formerly married women, further analysis of trends over time was performed to describe sexual activity among all unmarried women.

\section{Trends over time}

The proportion of married women who are currently sexually active has changed little over the last 30 years in the countries included in this study, except for some small increases in Eastern, Middle 


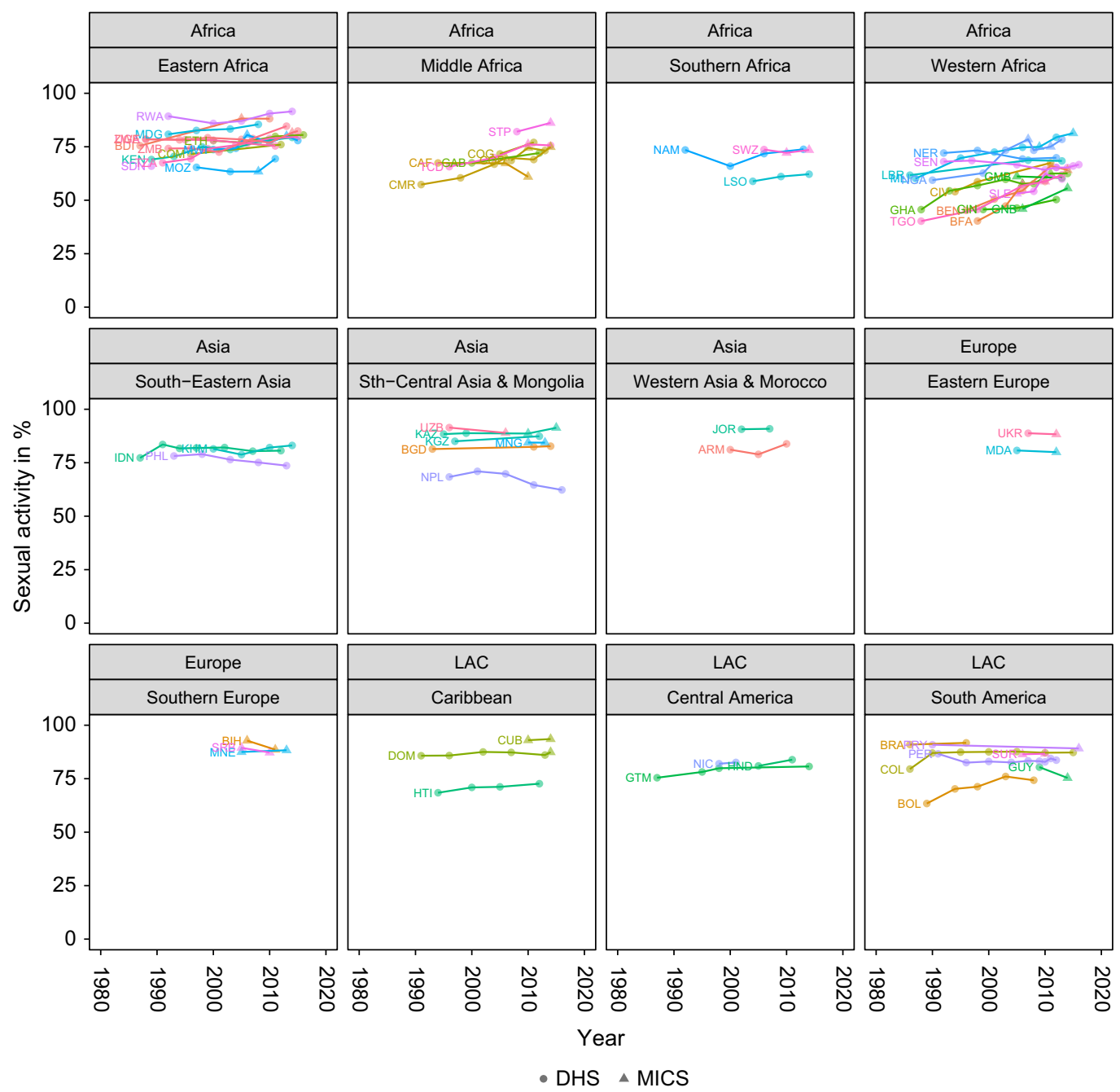

Figure 5. Trends in sexual activity in last 4 weeks among married women based on DHS and MICS micro datasets. Results shown by United Nations regions and sub-regions, except Mongolia, which is presented with South-Central Asia, and Morocco, which is presented with Western Asia. Country names represented by the three-letter ISO codes (see Table 1). LAC: Latin America and the Caribbean.

and Western Africa (Fig. 5). In some African countries (Mozambique in Eastern Africa and Namibia in Southern Africa), sexual activity of married women initially fell from the 1990s into the beginning of the 2000s, but then rose into the 2010s. Furthermore, there seems to be a slight downward trend of sexual activity of married women in Asian countries such as Nepal and the Philippines. There are insufficient data points over time for the countries in Europe to be able to determine clear patterns.

Figure 6 shows that changes in sexual activity among unmarried women over time are generally small and are also more diverse than among married women. Sexual activity among unmarried women has remained low in Asia, with only a slight upward trend in recent years for Kazakhstan. The picture is more complex in Africa. There are some declines in sexual activity among unmarried women in Eastern Africa (Kenya, Madagascar, Tanzania, Uganda, Zambia and Zimbabwe), and unclear patterns in Middle and Western Africa. Based on the limited data points for Southern 


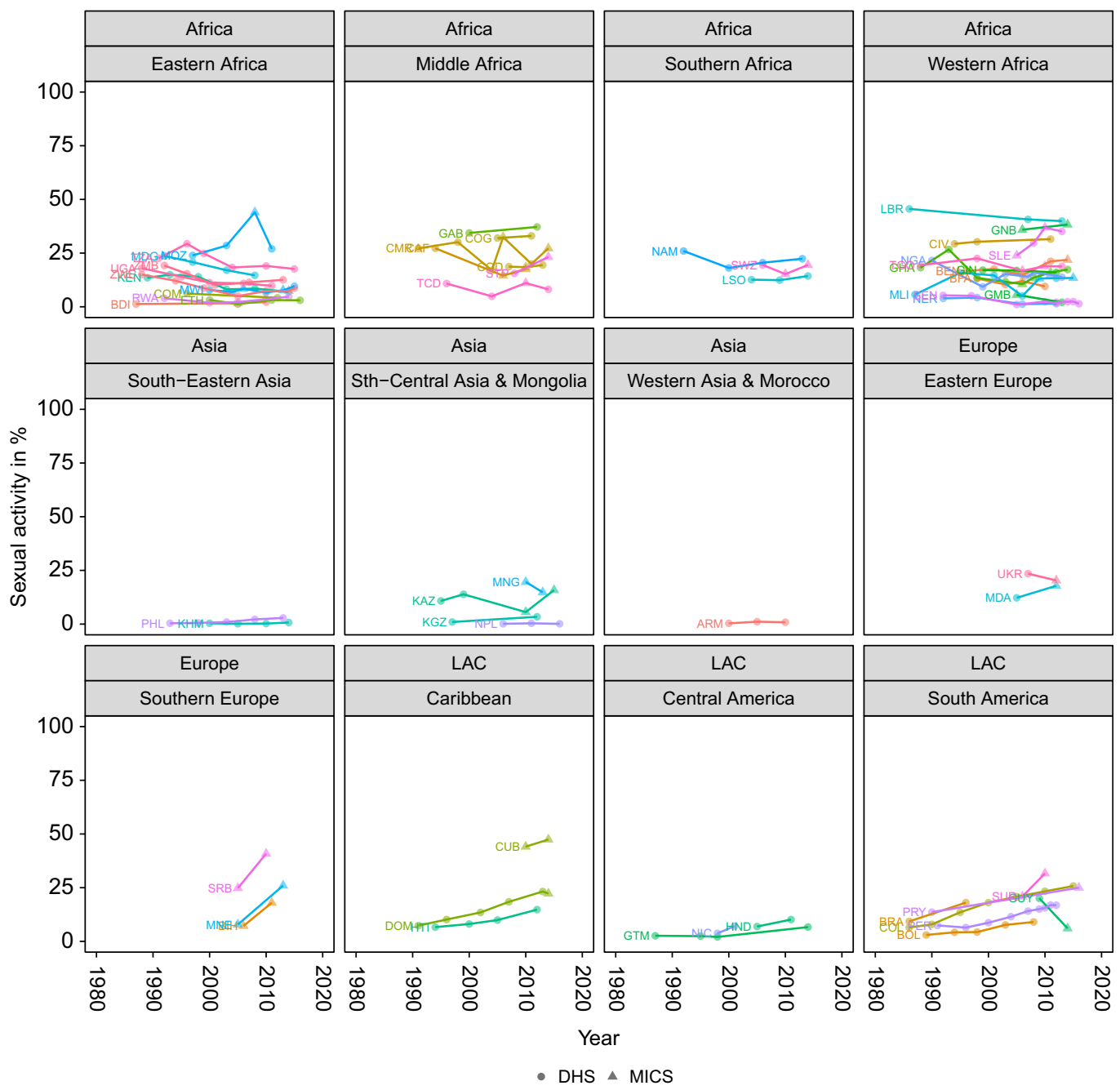

Figure 6. Trends in sexual activity in last 4 weeks among unmarried women based on DHS and MICS micro datasets. Results shown by United Nations regions and sub-regions, except Mongolia, which is presented with South-Central Asia, and Morocco, which is presented with Western Asia. Country names represented by the three-letter ISO codes (see Table 1). LAC: Latin America and the Caribbean.

Europe, there appear to be increases in sexual activity among unmarried women in Bosnia and Herzegovina, Montenegro and Serbia. There are general increases in sexual activity in most countries in Latin America and the Caribbean.

\section{Women's sexual activity by age}

There are significant differences by age in sexual activity among married women. In some countries in Eastern Africa and Western Asia, and in Morocco, sexual activity does not show much variation by age (Fig. 7). Countries in South-Eastern Asia, South-Central Asia (with exceptions of Nepal and Tajikistan), the Caribbean and South America display a slightly inverted U-shaped curve, while in Central American countries, a drop in sexual activity in the older reproductive ages is observed, especially in the $45-49$ age group. In a few countries, mostly in Africa (such as Guinea, 

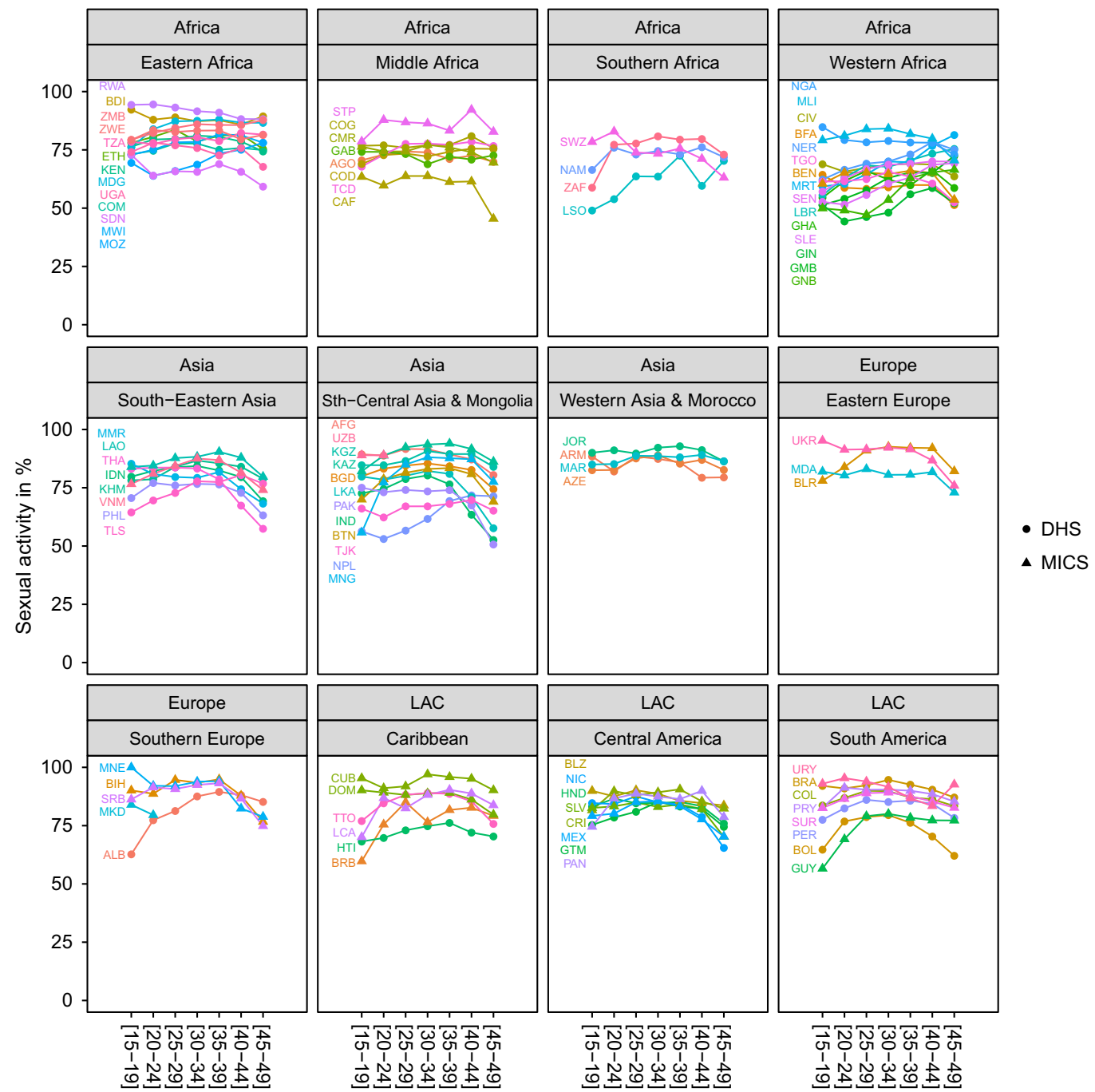

Age group

Figure 7. Proportion of married women sexually active in last 4 weeks by age based on DHS and MICS micro datasets. Results shown by United Nations regions and sub-regions, except Mongolia, which is presented with South-Central Asia, and Morocco, which is presented with Western Asia. Country names represented by the three-letter ISO codes (see Table 1). LAC: Latin America and the Caribbean.

Mozambique and Senegal), and in Nepal, there appears to be a small drop in sexual activity in some of the main childbearing ages.

Among unmarried women, the general pattern is a more pronounced inverted U-shape, skewed to the right (Fig. 8). The youngest and oldest unmarried women are the least sexually active. For most countries, the proportion of unmarried women who had intercourse in the last 4 weeks increased steeply from the younger age groups, peaked in the age group 25-29 years and then declined gradually in the later age groups. Countries where sexual activity has remaind relatively low at all ages are concentrated in Asia, with only three countries (Kazakhstan, Kyrgyzstan and Mongolia) showing the inverted U-shape pattern; and in some countries in Western African (Gambia, Mauritania, Niger and Senegal). It is important to bear in mind that unmarried women 

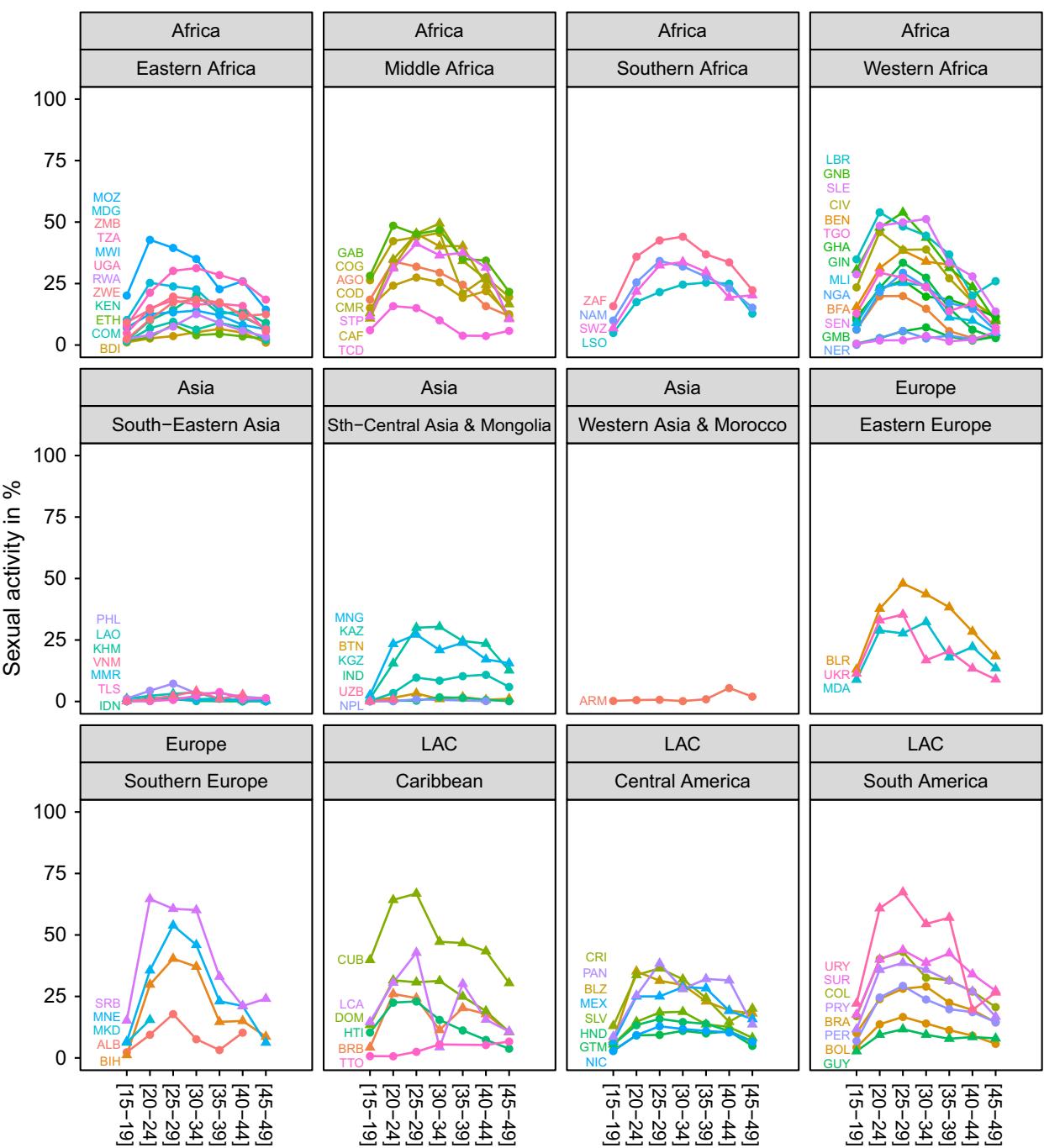

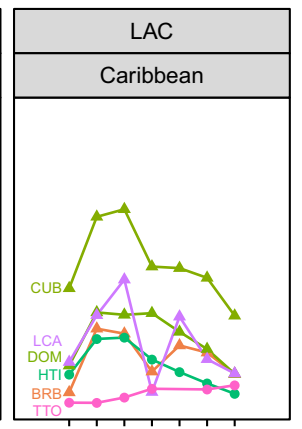

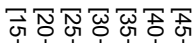

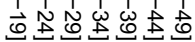

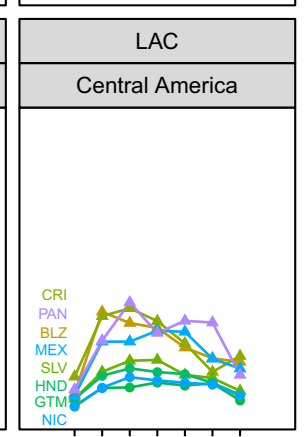

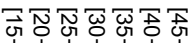

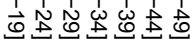

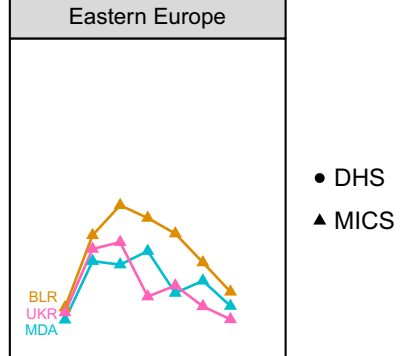

Age group

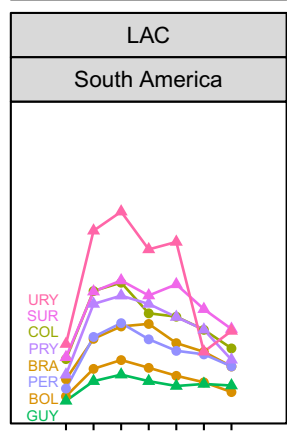

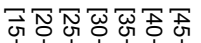

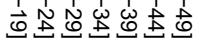

Figure 8. Proportion of unmarried women sexually active in last 4 weeks by age based on DHS and MICS micro datasets. Results shown by United Nations regions and sub-regions, except Mongolia, which is presented with South-Central Asia, and Morocco, which is presented with Western Asia. Country names represented by the three-letter ISO codes (see Table 1). LAC: Latin America and the Caribbean.

are concentrated in the youngest age groups, as many women transition into marriage or form a union later in life. Within the group of unmarried women, the proportion of formerly married women increases with age (United Nations, 2017b).

Among the countries that show the inverted U-shape by age, considerable cross-country differences exist in each region in the proportion of unmarried 15-19-year-old women who report being sexually active. The proportion of unmarried sexually active women in the age group 15-19 years is above $25 \%$ in some countries in Middle Africa (Congo and Gabon) and Western Africa (Guinea-Bissau, Liberia and Sierra Leone) and one country in Latin America and the Caribbean (Cuba). In all Asian countries included in this analysis, sexual activity among unmarried in this age group is $5 \%$ or less. 

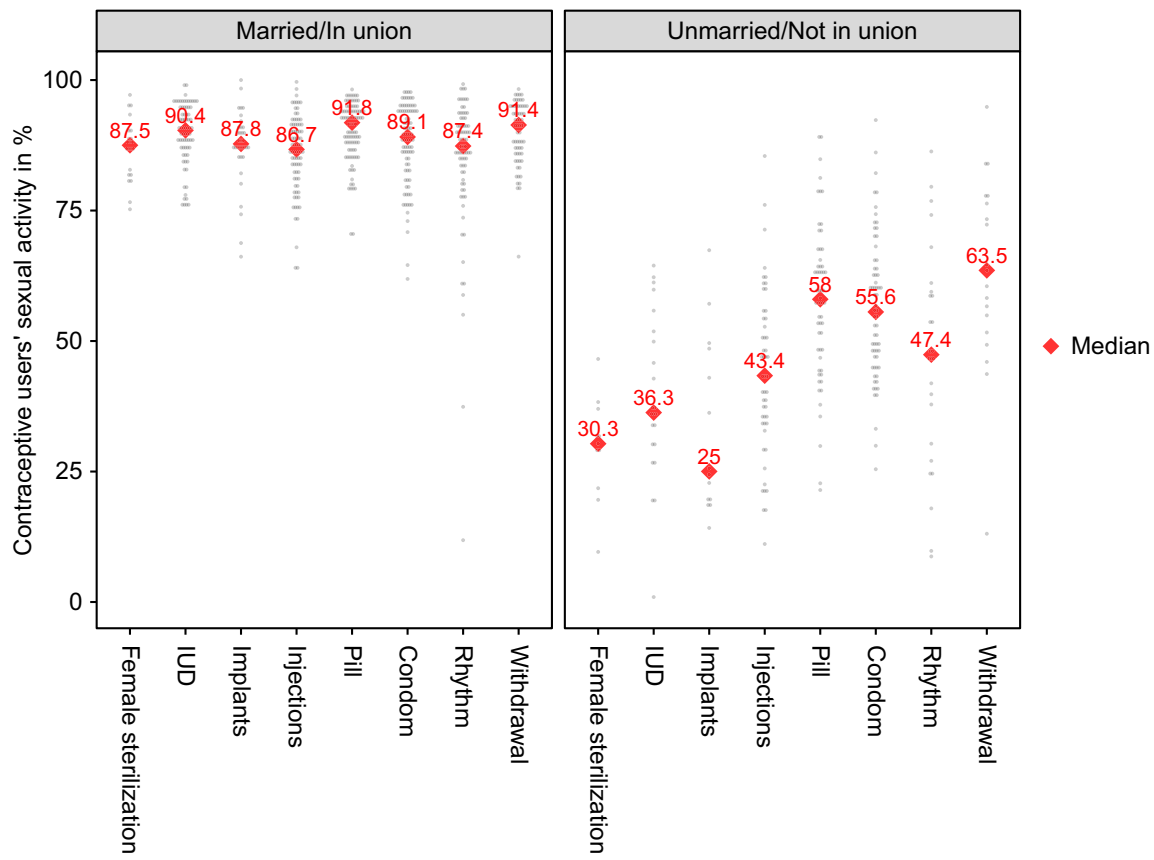

Figure 9. Proportion of contraceptive users who report being sexually active in the last 4 weeks, by contraceptive method based on DHS and MICS micro datasets; most recent estimates for each country (between 1987 and 2016). Only values based on more than 25 unweighted users of a specific method are included. LAC: Latin America and the Caribbean.

\section{Contraceptive use and sexual activity: implications for family planning indicators}

In order to better understand the impact of sexual activity on family planning indicators and to analyse the relationship between current use of contraceptive methods and sexual activity, it is important to recall how the relevant questions are asked in DHS and MICS surveys. For contraceptive use, women are asked the following question: Are you or your partner currently doing something or using any method to delay or avoid getting pregnant? If the answer is 'yes', the respondent is asked what method she or her partner is using. Note that the meaning of 'currently' is left to the interpretation of the woman. She may understand or believe this to mean today, within the last month or at the time of last sexual intercourse. For sexual activity, women are asked, 'When was the last time you had sexual intercourse?', which has a different time dimension to the contraceptive-use question. The questions are asked in different sections of the questionnaire. Both are sensitive matters, though the question on sexual activity is likely to be particularly sensitive when asked of unmarried women, which could lead to biased (under-) reporting. This section looks at the proportion of contraceptive users (by method) who are sexually active. Since sample sizes are small for some methods, only general patterns across methods are described, with a focus on medians, rather than teasing out geographical variations.

Not all women who report being contraceptive users are sexually active (defined as sexual intercourse in the last 4 weeks), both among unmarried and married women. Among married women, the proportion sexually active does not vary much by type of method used (Fig. 9). In more than half of the countries with available data, more than $90 \%$ of users of the intrauterine device (IUD), the pill or withdrawal report being sexually active in the last 4 weeks (the medians are $90.4 \%$ for IUD, $91.8 \%$ for the pill and $91.7 \%$ for withdrawal). Among unmarried women, there is much greater variation across countries and contraceptive methods. Reported sexual activity is higher among users of condoms (55.6\%), the pill (58.0\%) and withdrawal (63.5\%), compared with other methods. Sexual activity is lower among unmarried women using long-acting reversible methods 

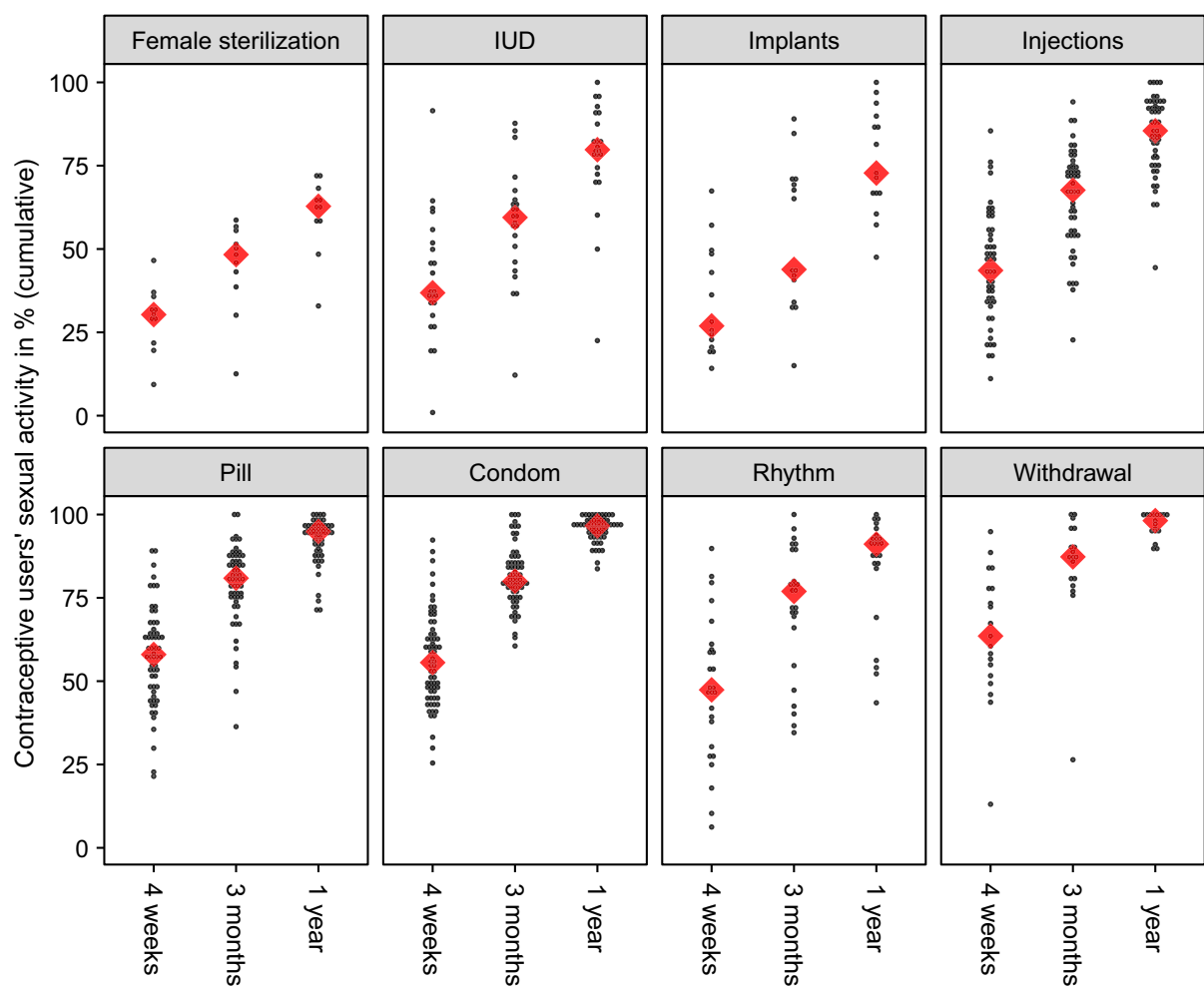

Median

Figure 10. Proportion of unmarried contraceptive users sexually active by sexual activity interval and by the most common contraceptive method based on DHS and MICS micro datasets; most recent estimates for each country (between 1987 and 2016). Only values based on more than 25 unweighted users of a specific method are included. LAC: Latin America and the Caribbean.

and sterilization; for example, it is $25 \%$ among implant users. The lower levels of sexual activity among unmarried women using long-acting methods might be related to the more difficult process to stop and start method use compared with short-acting methods. It could also be explained, as well as low levels of sexual activity among unmarried women using female sterilization (less than $50 \%$ in any survey), by the fact that the majority of these women are formerly married, who used permanent or long-acting methods at the time they were married and are still formally 'using' them (and reporting them in the survey) despite no longer being sexually active.

There are important implications of these results for reporting commonly used family planning indicators. When contraceptive users are restricted to only sexually active women, the number of contraceptive users among unmarried women is greatly reduced (given the generally low levels of reported sexual activity among unmarried contraceptive users presented in Fig. 9).

In all observed countries, the number of unmarried, sexually active women reporting female sterilization as their currently used contraceptive method is less than half of the number of all unmarried women reporting female sterilization. Additionally, in a majority of the countries, the number of currently sexually active unmarried users of IUDs, injections and implants is less than half of all unmarried women reporting the respective method use. Even if a longer time frame of last 3 months is applied to measure current sexual activity, the median value of the proportion of unmarried women using long-acting methods that are sexually active does not exceed $65 \%$ of all unmarried women using these methods (Fig. 10). The proportion of unmarried pill, condom and withdrawal users who report being sexually active within the last 3 months increases to around $75 \%$. The proportion of unmarried contraceptive users who are sexually active only approaches the levels for married women when the definition of current sexual activity for unmarried women is extended to intercourse in last year. 
Among both married and unmarried women, there are examples of apparent inconsistent responses to, or interpretations of, questions in cases where women report being currently using a coitus-dependent method (e.g. condom or withdrawal), but also report not being currently sexually active. This is probably due to the fact that the question on time of last sex is in a different section of the questionnaire to the question on current use of contraception: the time dimension for each question is different, the nature of the questions is sensitive leading to potentially biased responses and there may be some variation in the way that women interpret the meaning of the survey questions.

\section{Discussion}

The MICS and DHS datasets with harmonized age, marital status, contraceptive use and sexual activity variables were used to study trends in sexual activity across countries and over time with specific attention to differences by marital status and age. This is the first time that DHS and MICS data, to the fullest extent possible, have been used together to calculate estimates of recent sexual activity across a large number of countries (94 countries in total), to inform family planning indicators and need for reproductive health services.

The levels of sexual activity using different definitions of being currently sexually active, according to the timing of last sex (last 4 weeks, 3 months, 1 year, ever had sex) were compared to investigate the importance of the time frame used in the definition. The steep gradient in the cumulative proportion of women who are considered to be currently sexually active according to increasing time frame, shows how sensitive the definition of sexual activity is. The definition of current sexual activity as sexual intercourse within the last 4 weeks misses many unmarried women who were sexually active within a longer period of time (e.g. within the last year), who may be at risk of pregnancy even if they are only sporadically sexually active. This has an important implication for the calculation of family planning indicators among unmarried women, such as unmet need and demand satisfied, where sexual activity is used to determine exposure to the risk of pregnancy for this group of women. By restricting the temporal window to 4 weeks, it suggests there is less of a need for sexual and reproductive health programmes to serve unmarried women. Those producing estimates of these indicators may wish to consider extending the time frame of being currently sexually active beyond 4 weeks, to ensure unmarried women potentially at risk of pregnancy are not missed.

The finding that current sexual activity defined as sexual intercourse within the last 4 weeks misses unmarried women who were sexually active within a longer period of time has implications for family planning policy and programming. It indicates that a greater number of unmarried women are in need of family planning services than currently understood, which calls for increased funding for programmes and strategies to serve this group of women. Family planning providers should be trained to tailor their counselling to discuss family planning methods that are appropriate for those women who report being sporadically sexually active so that users choose a method with which they are satisfied.

Most married women are sexually active, but the proportion of sexually active can be as low as around $50 \%$ in some Western African countries (using the definition of sexual activity as intercourse within the last 4 weeks). The lowest levels of sexual activity among married women are in Benin, Burkina Faso, The Gambia, Guinea and Guinea-Bissau and could be due to postpartum or terminal abstinence practices. Bolivia and Guyana within South America, and Nepal and Tajikistan within South-Central Asia, stand out as different to the rest of the sub-region with a lower proportion of married women reporting being currently sexually active. Variations in the proportion of sexually active among married women are due to a number of factors, including temporary separations, practices concerning postpartum abstinence, the prevalence of polygamous unions, the extent of early and arranged marriages and expectation of partners about the marriage. It has been documented that temporary spousal separation, occurring due to 
seasonal migration, has inhibiting effects on childbearing through lower exposure to pregnancy (Massey \& Mullan, 1984; Agadjanian et al., 2011; Sevoyan \& Agadjanian, 2013).

In all countries included in this study, fewer than half of unmarried women are sexually active. Among unmarried women, large variations exist between countries within the major regions. Only countries from Asia included in this analysis show a particular regional pattern with generally a low proportion of unmarried women being sexually active. The diversity in sexual activity among unmarried women is difficult to explain and is related to a number of factors such as the norms about sex outside of marriage, gender equality, education, religiosity and other factors. For example, there is higher sexual activity among unmarried women in Kazakhstan compared with other countries in Central Asia and at the same time the proportion of the population reporting being Muslim in Kazakhstan is lower than other countries in the sub-region such as Kyrgyzstan and Tajikistan (Pew Research Centre, 2012). In the countries of Southern Europe, there is not much diversity in the proportion of sexually active married women, but there is noticeable variation for unmarried women. Sexual activity among unmarried women is low in Albania and Bosnia and Herzegovina, which are countries with a higher proportion of Muslim populations (Pew Research Centre, 2012).

Generally, there are small differences in sexual activity between never-married and formerly married women and, where different, in the majority of cases, sexual activity is higher among formerly married compared to never-married women. In some countries in Western Africa where never-married women are more sexually active than formerly married women, this may reflect the 'Grandmother rule', where women, upon becoming a grandmother, tend to abstain from sexual activity thereafter (Bledsoe, 2002).

Turning to trends over time, no generalized pattern could be observed. It is likely that the small rise over time in sexual activity among married women in Western Africa could be related to a decline in traditional practices such as postpartum abstinence. The decline in sexual activity among unmarried women observed in Eastern Africa could be in response to the HIV epidemic. The increase in sexual activity among unmarried women in the countries of the former Socialist Federal Republic of Yugoslavia may be related to modernization and the liberalization of attitudes, and to the increase in the age at first sexual intercourse and at first marriage or union formation.

For married women, there has been either little change across age groups or a slight inverted U-shaped curve of sexual activity by age. These results are in line with findings from other studies that report little variation in sexual activity across reproductive ages for countries in Asia and Africa (Brewis \& Meyer, 2005; Bell \& Bishai, 2017). The apparent decline in sexual activity in peak childbearing ages for married women in Guinea, Mozambique, Nepal and Senegal, may be related to long periods of sexual abstinence during the postpartum period or spousal separation due to temporary migration, as discussed above. A more pronounced inverted U-shape is apparent for unmarried women, with a peak in the age group 25-29 years in most countries. Sexual activity is common among unmarried adolescents in some countries in Middle and Western Africa and in Latin America and the Caribbean. This finding is broadly consistent with the substantial differentials between the ages at first sexual intercourse and at first marriage observed in many countries of sub-Saharan Africa and Latin America and the Caribbean, reported elsewhere (Bongaarts et al., 2017), and has key implications for the demand for sexual and reproductive health services by adolescents.

The proportion of women that report currently using contraception but not being sexually active is much larger among unmarried women and it varies significantly by contraceptive method. There are some inconsistencies between current method use and intercourse within the last 4 weeks; for example, a significant proportion of women reported not being sexually active while also currently using a coitus-dependent method such as condoms or withdrawal. Among both married and unmarried women, large cross-country variations in reported sexual activity are observed for users of rhythm methods, which could be related to different country-specific norms, or ways of interpreting questions on current contraceptive use and sexual 
activity. These discrepancies have an impact on indicators such as contraceptive prevalence among unmarried sexually active women and other indicators that use sexual activity in its calculations. The results of this analysis do not suggest that questions in surveys need to be changed, since there are many strengths in the way they are asked in DHS and MICS surveys. Rather, the results shed light on how the role of sexual activity - in terms of how it is defined, and whether and how it is included in calculations - impacts commonly used family planning indicators such as contraceptive prevalence and unmet need.

The relatively low overall level of sexual activity among contraceptive users has implications for the measurement of contraceptive use among unmarried women. The measurement of the degree of 'redundant protection' (Blanc \& Rutenberg, 1991) of contraceptive users currently not having sexual relations is important to better understand the effect of contraceptive use on fertility because the fertility-inhibiting effect of contraception might be overestimated. Another important consideration is related to family planning indicators for unmarried women. If the count of contraceptive users includes only sexually active unmarried women (defined as sexually active within the last 4 weeks), the count misses up to half of the total number of unmarried contraceptive users. This is especially so for women using permanent and long-acting methods. Therefore, the association between reported sexual activity and reported current use of contraceptive methods has implications for the measurement and interpretation of family planning indicators. As anticipated, it also has relevance for understanding the impact of contraceptive use on other reproductive health outcomes such as unintended pregnancies and abortions averted. This analysis shows complex patterns in sexual activity by age and marital status and therefore sexual activity should be integrated in analyses of exposure to pregnancy and resulting fertility patterns (Brown, 2000; Bell \& Bishai, 2017).

While this is an exploratory and descriptive piece of work, the results make some new contributions to the field. The findings invite further analysis of the inter-relationship between marital status, age, sexual activity, contraceptive use and pregnancies, given the widely varying levels of sexual activity among both married and unmarried women. Understanding levels and trends in sexual activity can also help to improve family planning programmes to serve the needs of different groups of women. This is particularly so for unmarried and young women, who are typically underserved. A better understanding of the levels and trends of sexual activity and contraceptive use of married and unmarried women over time provides useful information for reproductive health service programmatic planning.

Future research should also look into the design of survey questionnaires and its impact on reporting of sexual activity and contraceptive use. Surveys from DHS and MICS used in this study asked women of reproductive age about their current contraceptive use with the question 'Are you or your partner currently doing something or using any method to delay or avoid getting pregnant?' For sexual activity, the wording of the question was 'When was the last time you had sexual intercourse?' While the time period constituting the current use of contraception is left unspecified and therefore subject to the respondent's interpretation, for sexual intercourse the time is expressed as an exact time period. In other surveys questionnaire (for example, World Fertility Surveys, Gender and Generation Surveys and national surveys), there has been variability in how questions are asked, such as asking for contraceptive use within the month preceding the date of interview or at last sexual intercourse, and in how far apart the questions on contraceptive use and sexual activity are place (Kantorova et al., 2017). These variations invite further experimental research on the design of questionnaires.

There are a number of limitations of this study that deserve mention. Responses to survey questions on sexual activity may be subject to recall bias. There may also be under-reporting, particularly for never-married women. In countries where premarital sex is not regarded as acceptable, responses are likely to underestimate the extent of sexual activity (Curtis \& Sutherland, 2004; Wellings et al., 2006). Furthermore, it is important to keep in mind that while recency of sex may be associated with coital frequency, for the purposes of this study the measure 
of sexual activity was timing of last sex. Methodological differences between DHS and MICS could account for some of the differences in results observed over time and across countries, rather than being a true reflection of differences in sexual activity. This analysis was not designed to uncover systematic differences between DHS and MICS surveys. Although the study reports findings for a large number of countries, the results do not cover situations of other countries that do not have DHS and MICS programmes, so the findings are not necessarily representative of all the regions and sub-regions of the world.

Acknowledgements. The views expressed in this paper are those of the authors and do not necessarily reflect the views of the UN. The authors gratefully acknowledge Jorge Bravo, Helena Cruz Castanheira, Stephen Kisambira, Karoline Schmid, Mark C. Wheldon and Guangyu Zhang for their helpful comments on the technical paper. The authors also acknowledge the insights offered by the discussant, Bruno Masquelier, and others who attended the presentation of this paper at the 28th International Population Conference of the International Union for the Scientific Study of Population (IUSSP), in Cape Town, South Africa, 29th October to 4th November 2017. The authors thank the anonymous reviewers for their careful reading of the manuscript and their insightful comments and suggestions. The article was previously made available as a technical paper of the United Nations Population Division (unpopulation.org) and has been slightly revised for this publication as a result of the peer review process.

Funding. This work was supported, in part, by Grant No. OPP1183453, Making Family Planning Count, from the Bill \& Melinda Gates Foundation.

Conflicts of Interest. The authors have no conflicts of interest to declare.

Ethical Approval. The authors assert that all procedures contributing to this work comply with the ethical standards of the relevant national and institutional committees on human experimentation and with the Helsinki Declaration of 1975, as revised in 2008 .

\section{References}

Agadjanian V, Yabiku ST and Cau B (2011) Men's migration and women's fertility in rural Mozambique. Demography 48(3), 1029-1048.

Bell SO and Bishai D (2017) Unmet need and sex: investigating the role of coital frequency in fertility control. Studies in Family Planning 48(1), 39-53.

Blanc A and Rutenberg N (1991) Coitus and contraception: the utility of data on sexual intercourse for family planning programs. Studies in Family Planning 22(3), 162-173.

Blanc A and Way A (1998) Sexual behavior and contraceptive knowledge and use among adolescents in developing countries. Studies in Family Planning 29(2), 106-116.

Bledsoe C (2002) Contingent Lives: Fertility, Time and Aging in West Africa. University of Chicago Press, Chicago.

Bongaarts J (1978) A framework for analyzing the proximate determinants of fertility. Population and Development Review 4(1), 105-132.

Bongaarts J (2015) Modeling the fertility impact of the proximate determinants: time for a tune-up. Demographic Research 33(19), 535-560.

Bongaarts J, Mensch BS and Blanc AK (2017) Trends in the age at reproductive transitions in the developing world: the role of education. Population Studies 71(2), 139-154.

Bradley SEK and Casterline JB (2014) Estimating unmet need: history, theory and measurement. Studies in Family Planning 45(2), 123-150.

Bradley SEK, Croft TN, Fishel JD and Westoff CF (2012) Revising unmet need for family planning. DHS Analytical Studies No. 25. ICF International, Calverton, MD.

Brewis A and Meyer M (2005) Marital coitus across the life course. Journal of Biosocial Science 37(4), 499-518.

Brown MS (2000) Coitus, the proximate determinant of conception: inter-country variance in sub-Saharan Africa. Journal of Biosocial Science 32(2), 145-159.

Buvé A, Lagarde E, Caraël M, Rutenberg N, Ferry B, Glynn JR et al. (2001) Interpreting sexual behaviour data: validity issues in the multicentre study on factors determining the differential spread of HIV in four African cities. AIDS 15 (Supplement 4), S117-S126.

Caldwell J and Caldwell P (1990) High fertility in sub-Saharan Africa. Scientific American 262(5), 82-89.

Cleland J and Ali M (2006) Sexual abstinence, contraception and condom use by young African women: a secondary analysis of survey data. The Lancet 368, 1788-1793. 
Cleland J, Boerma JT, Carael M and Weir SS (2004) Monitoring sexual behavior in general populations: a synthesis of lessons of the past decade. Sexually Transmitted Infections 80 (Supplement II), ii1-ii7.

Curtis SL and Sutherland EG (2004) Measuring sexual behaviour in the era of HIV/AIDS: the experience of Demographic and Health Surveys and similar enquiries. Sexually Transmitted Infections 80 (Supplement II), ii22-ii27.

DHS StatCompiler (2017) Current Use of Any Method of Contraception (Sexually Active Unmarried Women). Demographic and Health Survey. URL: https://www.statcompiler.com/en/ (accessed 15th June 2017).

Fabic MS and Becker S (2017) Measuring contraceptive prevalence among women who are at risk of pregnancy. Contraception 96(3), 183-188.

Gage A and Meekers D (1994) Sexual activity before marriage in sub-Saharan Africa. Biodemography and Social Biology 41(1-2), 44-60.

Gage-Brandon A and Meekers D (1993) Sex, contraception and childbearing before marriage in sub-Saharan Africa. International Family Planning Perspectives 19(1), 14-18.

Kantorová V, Dasgupta ANZ, Ueffing P, Wheldon M and Soerjanto N (2017) Who Collects What on the Current Use of Contraception? A Review of Survey Data Available for the Estimation of Contraceptive Prevalence. Technical Paper 2017/12. Department of Economic and Social Affairs, Population Division, United Nations, New York.

Kim-Godwin YS (2003) Postpartum beliefs and practices among non-Western cultures. American Journal of Maternal/Child Nursing 28(2), 74-78.

MacQuarrie KLD (2014) Unmet need for family planning among young women: levels and trends. DHS Comparative Reports No. 34. ICF International, Rockville, MD.

Massey M and Mullan B (1984) A demonstration of the effect of seasonal migration on fertility. Demography 21(4), 501-517.

Meekers D (1994) Sexual initiation and premarital childbearing in sub-Saharan Africa. Population Studies 48(1), 47-64.

Mishra V, Agrawal P, Alva S, Gu Y and Wang S (2009) Changes in HIV related knowledge and behaviours in sub-Saharan Africa. DHS Comparative Reports No. 24. ICF Macro, Calverton, MD.

Pew Research Centre (2012) The Global Religious Landscape: A Report on the Size and Distribution of the World's Major Religious Groups as of 2010. URL: http://www.pewforum.org/2012/12/18/global-religious-landscape-exec/ (accessed 15th June 2017).

Pew Research Centre (2014) Global Views on Morality. URL: http://www.pewglobal.org/2014/04/15/global-morality/ (accessed 15th June 2017).

Rossier C and Corker J (2017) Contemporary use of traditional contraception in sub-Saharan Africa. Population and Development Review 43(1), 192-215.

Sathar Z and Chidambaram VC (1984) Differentials in contraceptive use. WFS Comparative Studies No. 36. International Statistical Institute, Voorburg, the Netherlands.

Selin H and Stone PK (2009) Childbirth Across Cultures: Ideas and Practices of Pregnancy, Childbirth and the Postpartum. Springer, the Netherlands.

Sevoyan A and Agadjanian V (2013) Contraception and abortion in a low-fertility setting: the role of seasonal migration. International Perspectives on Sexual and Reproductive Health 39(3), 124-132.

Stover J (1998) Revising the proximate determinants of fertility framework: what have we learned in the past 20 years? Studies in Family Planning 29(3), 255-267.

United Nations (2015) Resolution 70/1. Transforming Our World: The 2030 Agenda for Sustainable Development. A/RES/70/1. General Assembly, United Nations.

United Nations (2017a) World Contraceptive Use by Marital Status and Age 2017. Department of Economic and Social Affairs, Population Division, United Nations, New York. URL: http://www.un.org/en/development/desa/population/ publications/dataset/contraception/wcuma2017.shtml (accessed 15th June 2017).

United Nations (2017b) World Marriage Data 2017. Department of Economic and Social Affairs, Population Division, United Nations, New York. URL: http://www.un.org/en/development/desa/population/theme/marriage-unions/WMD2017.shtml (accessed 15th June 2017).

United Nations (2019) Global SDG Indicators Database. Metadata repository. Indicator 3.7.1 Statistics Division, United Nations. New York. URL: https://unstats.un.org/sdgs/metadata/files/Metadata-03-07-01.pdf (accessed 26th November 2019).

Wang W, Alva S and Wang S (2012) HIV-related knowledge and behaviours among people living with HIV in eight high HIV prevalence countries in sub-Saharan Africa. DHS Analytical Studies No. 29. ICF International, Calverton, MD.

Wellings K, Collumbien M, Slaymaker E, Singh S, Hodges Z and Patel D (2006) Sexual behaviour in context: a global perspective. The Lancet 368(9548), 1706-1728.

Zaba B, Pisani E, Slaymaker E and Boerma JT (2004) Age at first sex: understanding recent trends in African demographic surveys. Sexually Transmitted Infections 80(2), 28-35.

Cite this article: Ueffing P, Dasgupta ANZ, and Kantorová V (2020). Sexual activity by marital status and age: a comparative perspective. Journal of Biosocial Science 52, 860-884. https://doi.org/10.1017/S002193201900083X 